\title{
DEVELOPMENTAL STAGES OF EMBRYO-LIKE BODIES IN TERATOMA TESTIS
}

\author{
BY \\ R. WINSTON EVANS \\ From the David Lewis Northern Hospital, Liverpool
}

(RECEIVED FOR PUBLICATION JULY 11, 1956)

Small bodies, comparable in their morphology with that of the early developmental stages of mammalian embryos, are observed uncommonly in certain testicular teratomata (Melicow, 1940; Dixon and Moore, 1953; Evans, 1956); and although an enormous number of these embryolike structures may be scattered haphazardly throughout a teratomatous growth, it is only rarely that such bodies (Figs. 2, 5) mimic closely the form of normal early human embryos (Fig. 1).

In the case to be described numerous embryoid bodies were present in many areas of a testicular teratoma and many of these bore a remarkable resemblance to normal early primate embryos. The mimicry was so extraordinary that it was considered worth while studying a few of these embryo-like structures in detail in serial sections so that their anatomy could be compared with that of normal presomite mammalian embryos of corresponding morphological stages of development. An attempt was made also to trace the various ontogenetic phases in the hope of gathering some information relevant to the evolution and ultimate fate of these structures.

\section{Clinical Note and Details of Specimen}

The testicular teratoma was removed by $\mathrm{Mr}$. Philip Hawe from a patient aged 41 years; the growth had been present for six months. Five years after operation the man was alive and well, exhibiting no clinical evidence of recurrence or metastases.

The tumour formed an ovoid mass measuring $6 \mathrm{~cm}$. by $5 \mathrm{~cm}$. by $5 \mathrm{~cm}$. in its main axes. Its cut surface presented a variegated appearance with many small cystic spaces and glistening, blue, translucent foci of cartilage.

Histologically, apart from numerous embryolike structures, there were areas of tumour exhibiting well-differentiated cartilage, smooth muscle, nerve tissue, large and small epithelial tubules, glandular components and cystic spaces lined by cuboidal and sometimes columnar epithelium. There were also pilo-sebaceous units, cornifying structures, and primordia of enamel organs. In addition, undifferentiated embryonic cells were observed and these, for the most part, were arranged in sheets and cords. Foci of cytotrophoblastic and syncytiotrophoblastic differentiation also were noted.

No hormone determinations were carried out.

\section{Anatomically Well-formed Triploblastic Embryoid Bodies}

In well-formed embryoid bodies structures can be discerned easily which resemble, both in form and relation to one another, the amniotic cavity, embryonic disc, intra-embryonic mesoderm and yolk sac, and gut endoderm of a normal presomite human embryo (Fig. 1).

Four such morphologically well-formed embryolike structures were followed in series, and consecutive sections of each embryoid body were photographed at a constant magnification. No markers were inserted into the paraffin blocks, but arbitrary points and lines were selected on the photomicrographs so that rough graphic representations of the embryoid bodies could be constructed. The sections were cut at 5 microns.

The overall shape of the embryoid bodies varied from approximately spheroidal to globular and pyriform; sometimes an embryoid body was cylindroid in outline. Such bodies varied also in size and their calculated main axes are given in the Table. Although in this table measurements in two

TABLE

\begin{tabular}{c|c|c|c}
\hline \multirow{2}{*}{ Embryo } & Height (mm.) & Width (mm.) & Length (mm.) \\
\cline { 2 - 3 } A & 0.7 & 0.35 & 0.30 \\
B & 0.28 & 0.28 & 0.30 \\
C & 0.41 & 0.18 & 0.21 \\
E & 0.36 & 0.30 & 0.40 \\
\hline
\end{tabular}




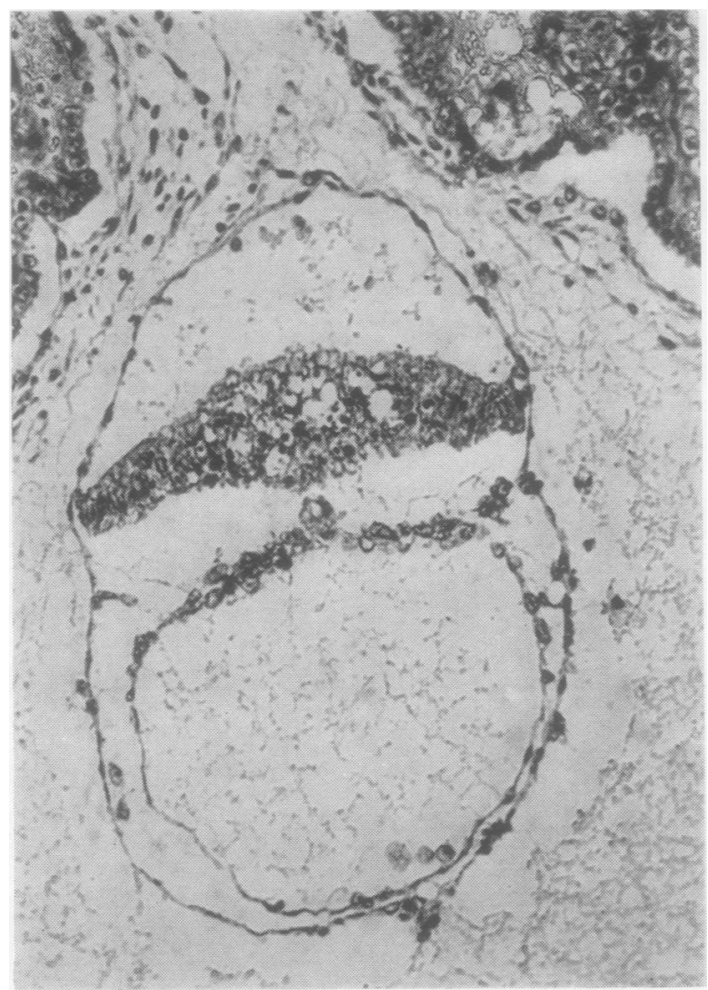

FiG. 1.-Presomite-human embryo, age approximately 17-18 days. Section is through Hensen's node. The embryonic plate, due to a fixation artefact, is dislocated from the gut endoderm. The intra- and extra-embryonic mesoderm is in continuity and angioblastic tissue is present on the wall of the yolk sac. Haematoxylin and eosin $\times 180$.

planes are listed as width and length the terms are used in a descriptive sense and have no anatomical significance, for no cephalo-caudal orientation of these embryoid bodies is possible; the values given for the main axes serve only to indicate the general contours and the variations which occur in the size and shape.

A chorionic membrane with villi is not distinguishable as such, but adjacent to the " amnion" or "yolk sac," or both, of these embryoid bodies a few syncytial giant cells are sometimes seen (Figs. 7,10 ). Frequently such a body terminates in a structure which may be interpreted as a type of "body stalk" (Figs. 10, 11); this is circular or oval in cross-section and composed of concentrically disposed spindle cells often arranged loosely to impart a characteristic appearance. Within or immediately adjacent to this structure cytotrophoblastic and syncytiotrophoblastic differentiation occurs in small foci; also within this distinctive corpuscle a tubule is frequently included.
The homologue, in embryoid bodies, of the yolk sac and gut endoderm of normal early embryos varies in size and shape. Commonly it extends beyond the limits of the "embryonic plate" and is often continued within the stalk-like terminal corpuscle, sometimes as a narrow duct (Fig. 8) but now and again as a dilated flask or sausage-shaped diverticulum (Figs. 13, 15, 16). The narrow duct type of prolongation may be considered as homologous with the primate type of allantois, but the dilated form of outpouching corresponds more to the allantois of carnivores and ungulates.

Sometimes the yolk-sacs of two neighbouring embryoid bodies communicate with each other through a small opening; at other times two embryo-like structures share a common "yolk sac" (Fig. 9).

The yolk sac of embryoid bodies may be composed completely or partially of flattened, cuboidal, or columnar cells, and these are disposed generally as a single layer. When, however, such a yolk sac protrudes beyond the limits of the embryonic plate there is a tendency for the cells to become vacuolated and arranged in two or more layers; especially toward the blind end of the outpouching, representing the allantois, endodermal cells may hypertrophy and proliferate in solid masses (Fig. 15).

Although the gut endoderm is usually sharply demarcated from the embryonic plate and mesoderm (Figs. 2, 3, 4, 6), at various points it appears to mingle imperceptibly with the latter (Figs. 5 , 12, 13). In one embryoid body (Fig. 6) a patch of thickened endoderm forms a conspicuous feature in the roof of the yolk sac and may be considered as homologous with the primordium of the prochordal plate of the normal embryo. However, no structure corresponding to a head process could be identified at either extremity of this abnormal prochordal plate.

An amorphous coagulum (Fig. 9) and, infrequently, a few isolated desquamated cells are formed within the yolk-sac. Angioblastic tissue was not noted in association with the yolk sac.

The amnion of embryoid bodies is dome-shaped or bell-like (Figs. 2, 6,7) and shows much variation in size. Whereas sometimes the transition is gradual, in most cases, as in the normal presomite embryo, the amnion arises abruptly from the margins of the embryonic plate (cf. Figs. 1 and 2) and apparently consists of a single ectodermal layer, for any delicate external mesodermal layer is difficult to perceive and distinguish from the layers of mesoblastic cells which in concentric manner invest closely the whole embryoid body. 


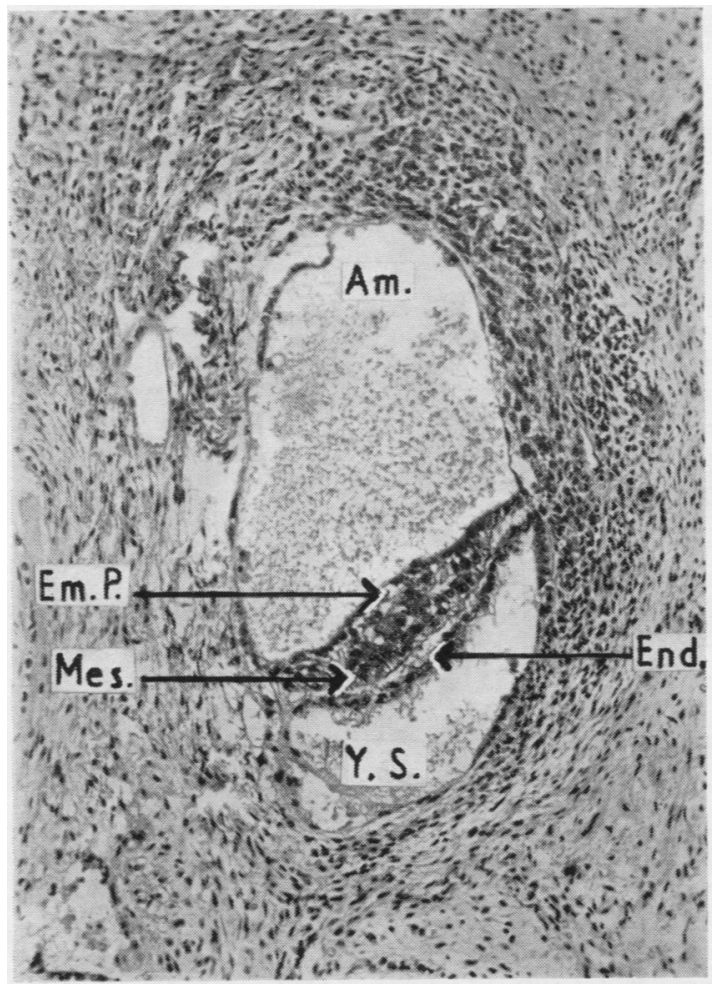

FIG. 2

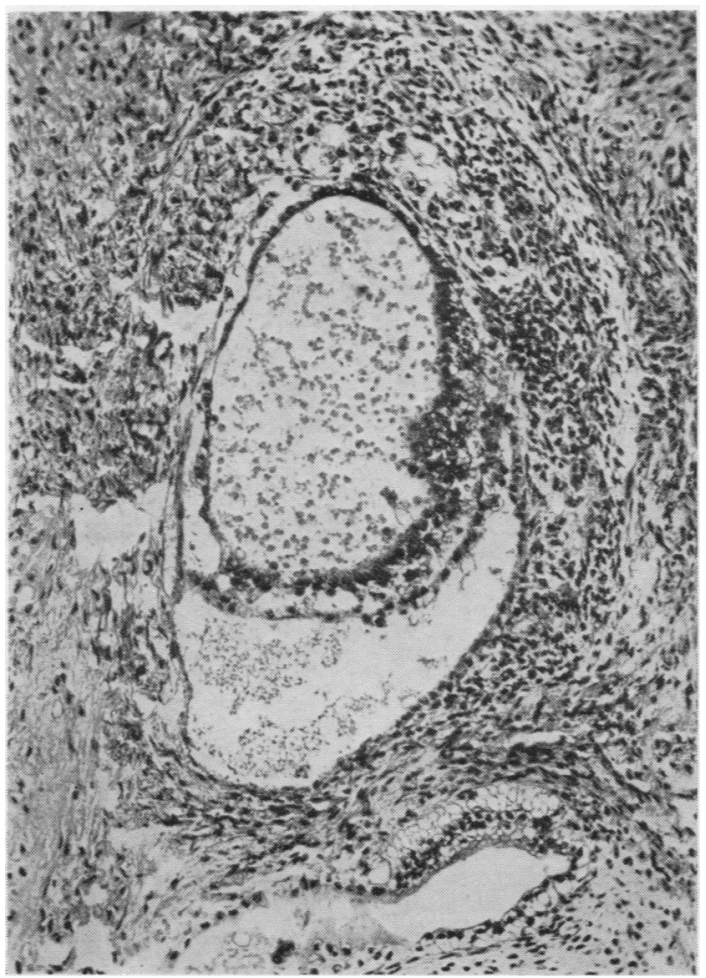

Fig. 3

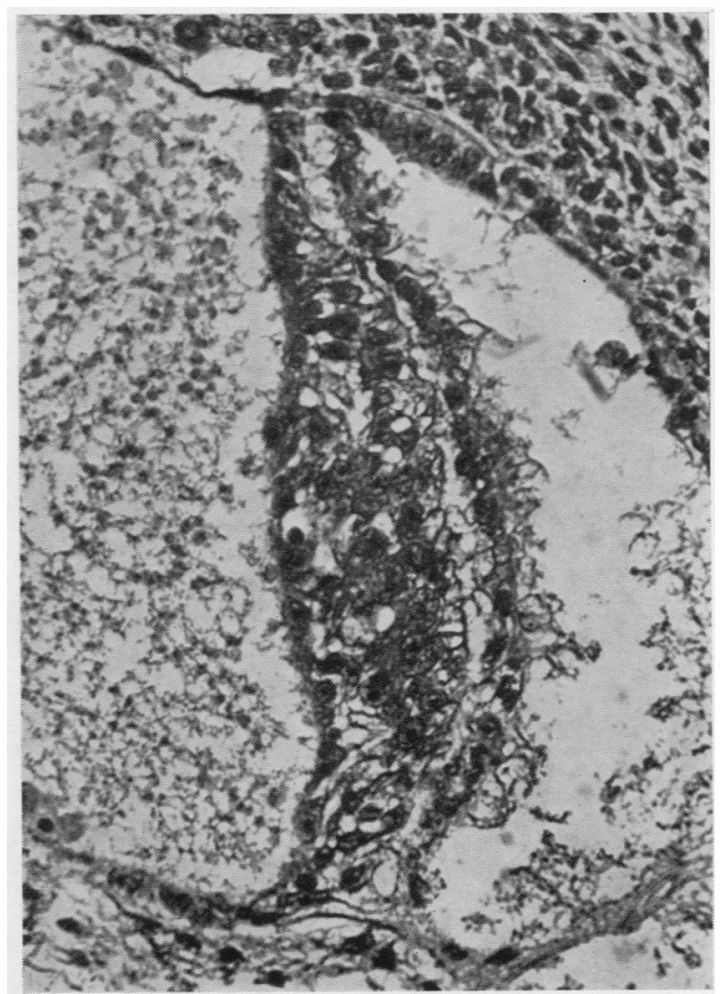

Fig. 4

Fig. 2.-Well-formed, reasonably symmetrical embryoid body showing a large amniotic cavity (Am.), an obliquely positioned embryonic plate (Em.P.), intra-embryonic mesoderm (Mes.), yolk sac (Y.S.), and gut endoderm (End.). The section is through the region of the "primitive streak." Haematoxylin and eosin $\times 104$.

FIG. 3.-This section is 250 microns removed from the previous figure. A diverticulum is developing in the roof of the yolk sac and gut endoderm in relation to an abnormally situated nodal proliferation in the embryonic plate. In this section the amnion is obviously double layered. Haematoxylin and eosin $\times 104$.

Fig. 4.-Detail of Fig. $2 \times 250$.

Uncommonly, as in Fig. 3, a double layer is obvious and the external mesodermal membrane is well marked. The "amnion" is composed usually of flattened cells, but sometimes cuboidal and columnar cells, frequently of clear aspect, are developed also, often in a patchy manner (Figs. $12,13,14)$.

The embryonic disc varies in its configurâtion in different embryoid bodies; in some it is, reasonably symmetrical and convex about and in the two upright planes, whereas in other cases no symmetrical pattern is maintained and this asymmetry in the position of the embryonic plate is reflected by a corresponding asymmetry of the yolk sac and gut endoderm (Fig. 3). 
EMBRYO B

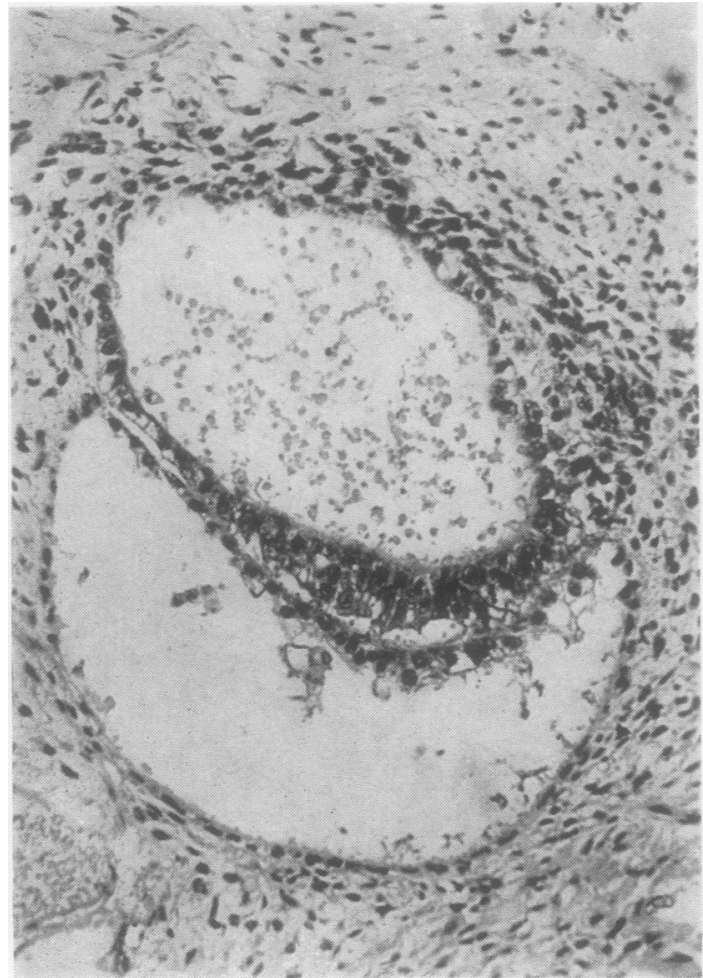

Fig. 5

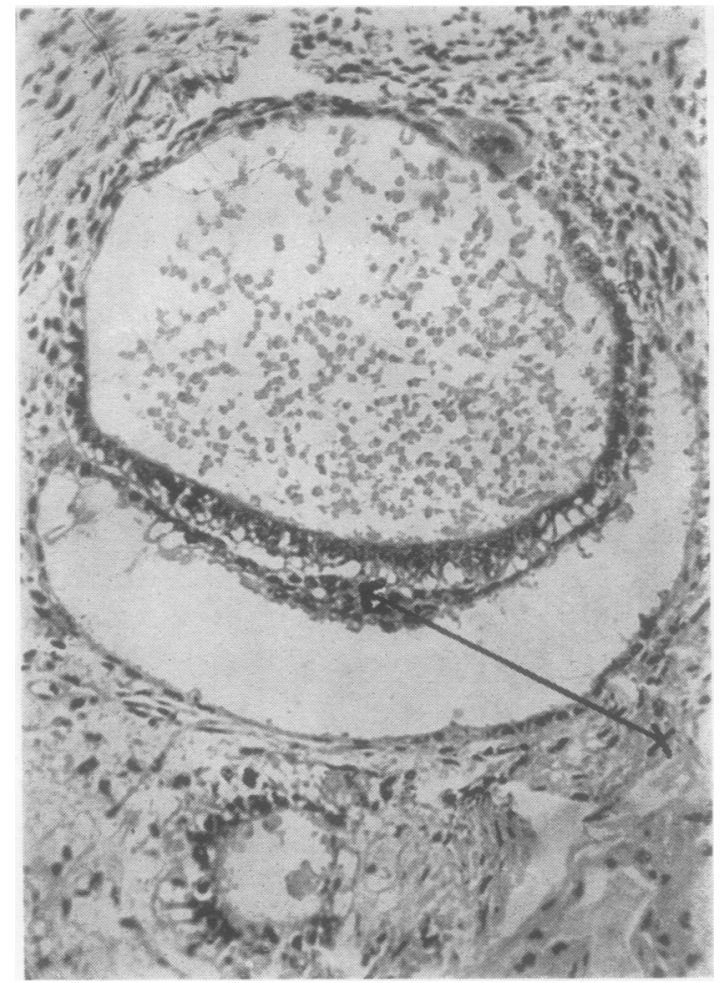

FIG. 6

\section{EMBRYOID BODY C}

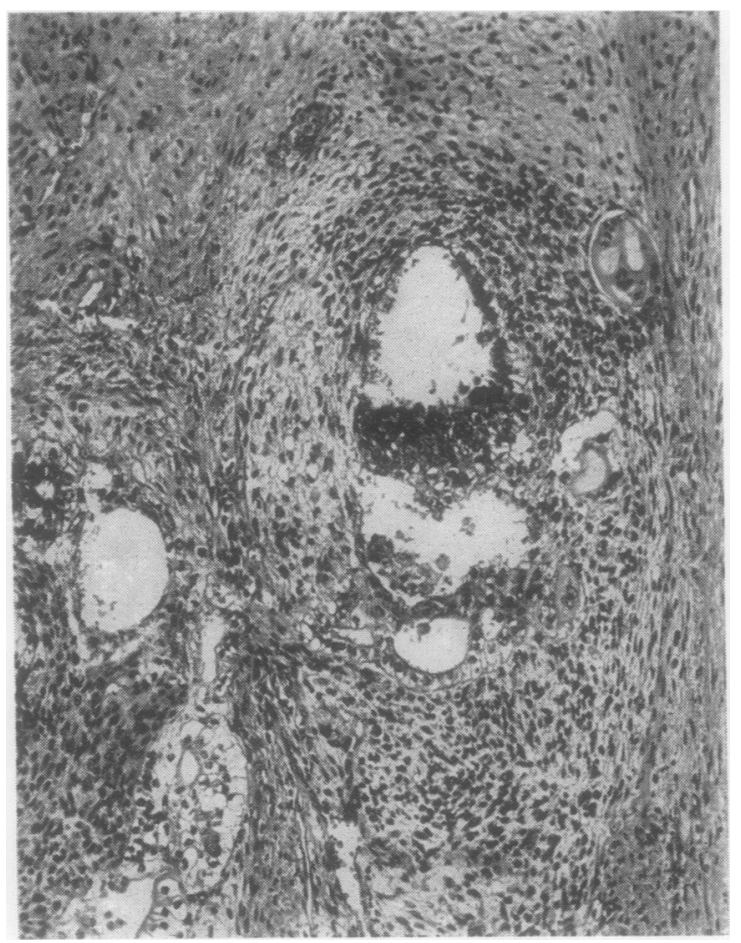

Fig. 7

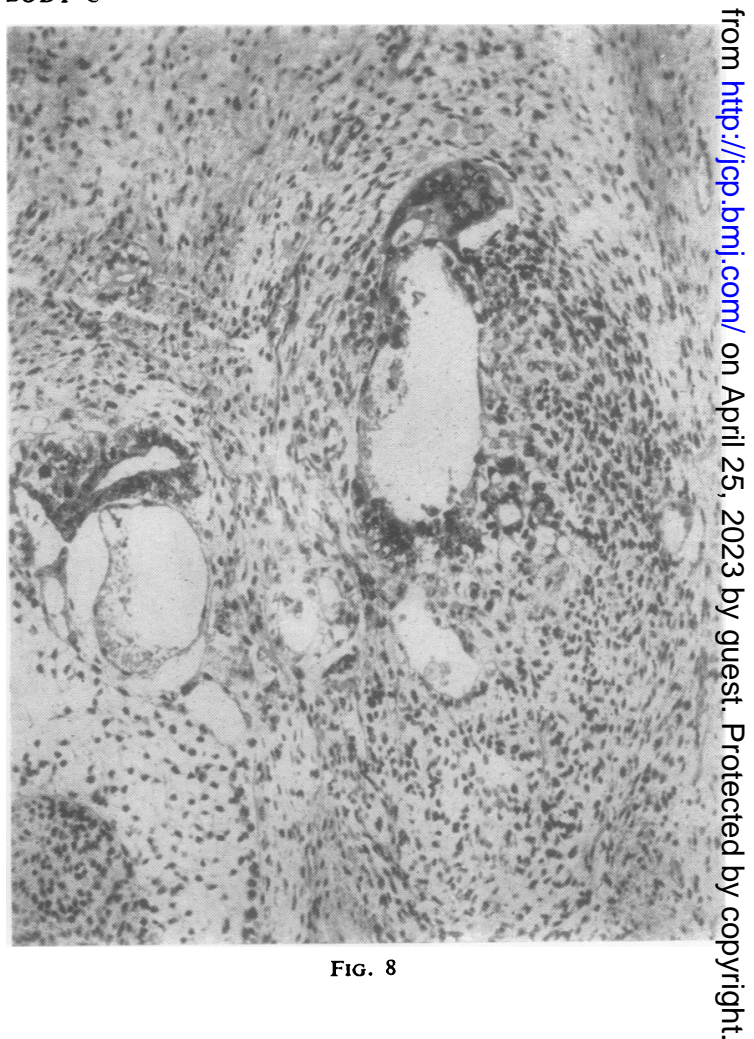


EMBRYOID BODY D

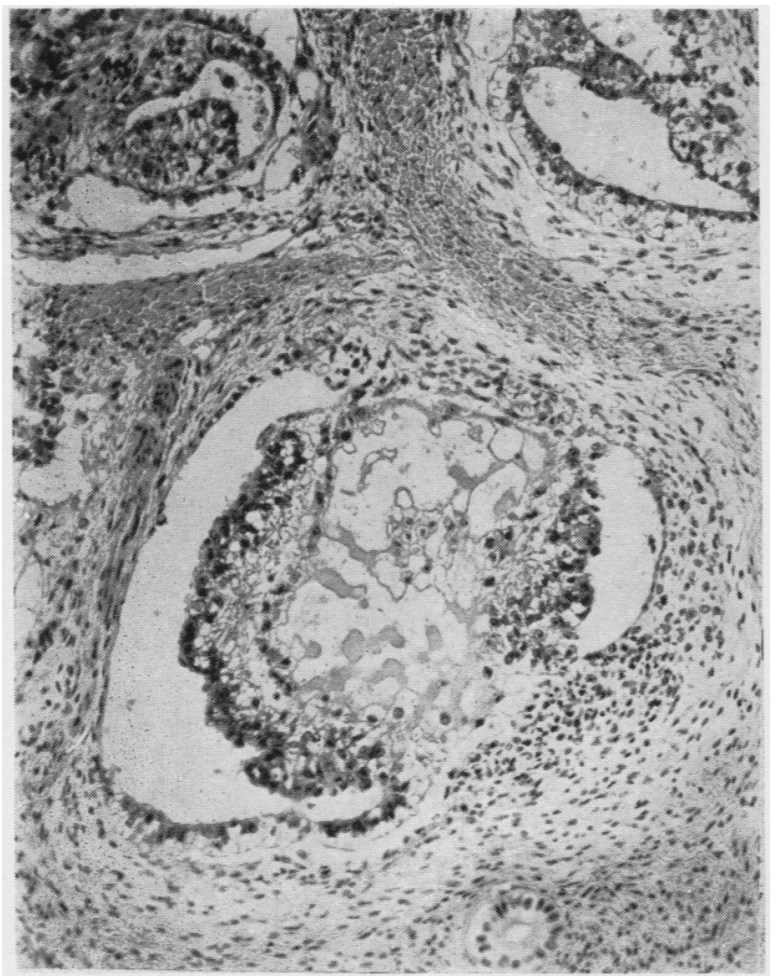

Fig. 9

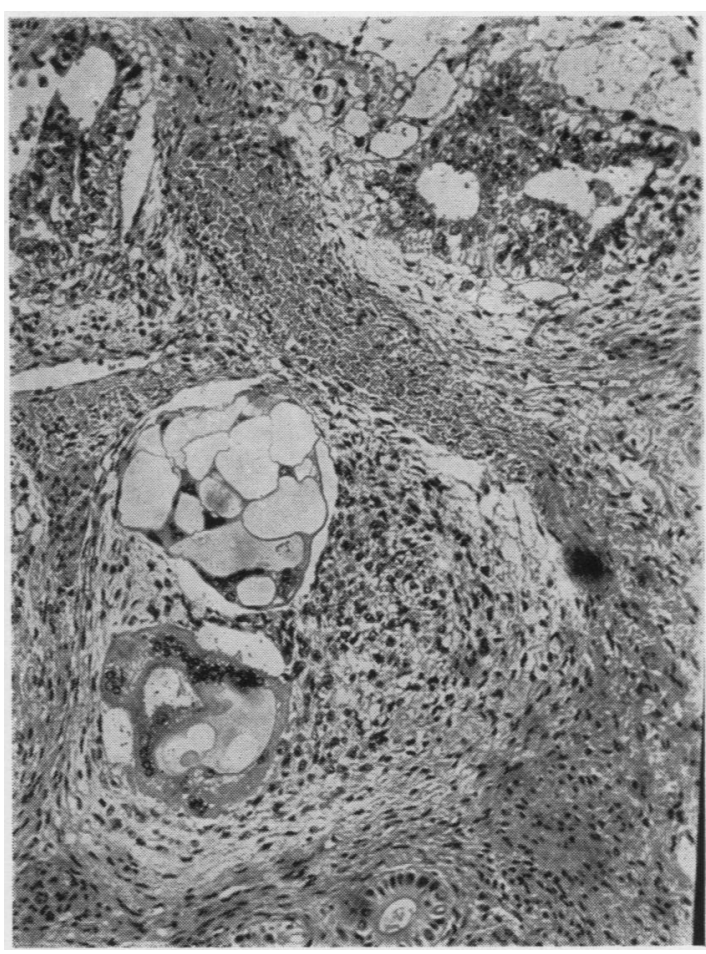

FIG. 11

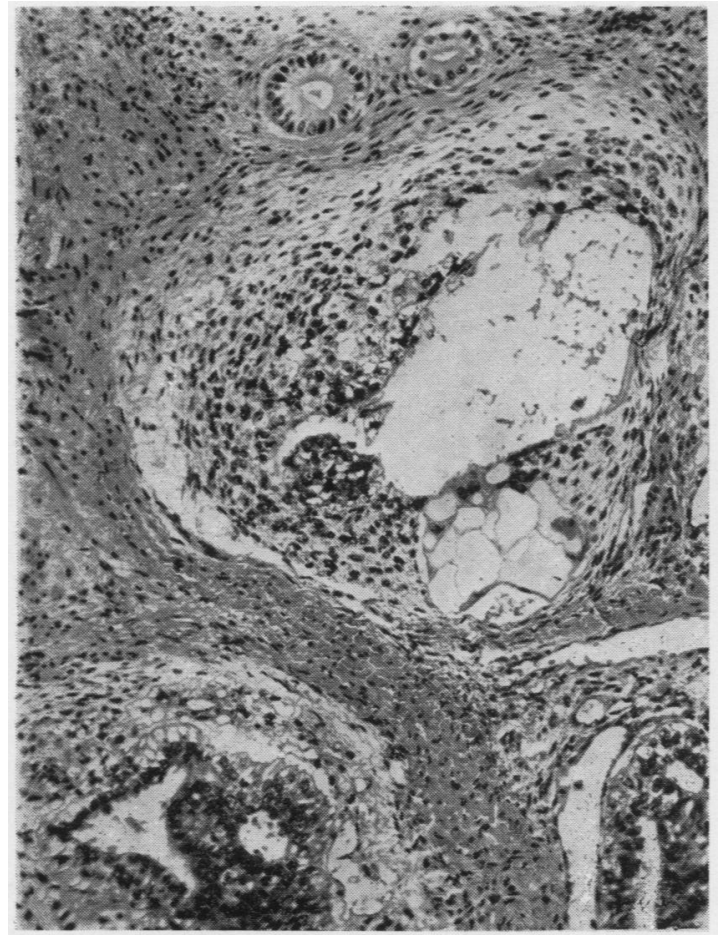

Fig. 5.-Section through region of "primitive streak." The endoderm is well separated from the ectoderm except at the righthand side of the figure. The mesoblastic cells possess cytoplasmic prolongation. Haematoxylin and eosin $\times 230$.

Fig. 6. Section 50 microns from Fig. 5 shows a thickening in the roof of the yolk sac. ? homologue of prochordal plate $(X)$. Haematoxylin and eosin $\times 230$.

Figs. 7 and 8.-Small embryoid body near "body stalk" end showing syncytial giant cells in association with amnion and yolk sac. Haematoxylin and $\operatorname{cosin} \times 126$.

Fig. 9.-Embryoid body containing two embryonic plates and a common yolk sac. Haematoxylin and $\operatorname{cosin} \times 130$.

FIG. 10.- " Body stalk" of embryoid body showing extension into it of yolk sac. Haematoxylin and $\operatorname{cosin} \times 130$.

Fig. 11.-Vacuolated syncytial giant cells in " body stalk." Haematoxylin and $\operatorname{cosin} \times 130$. 


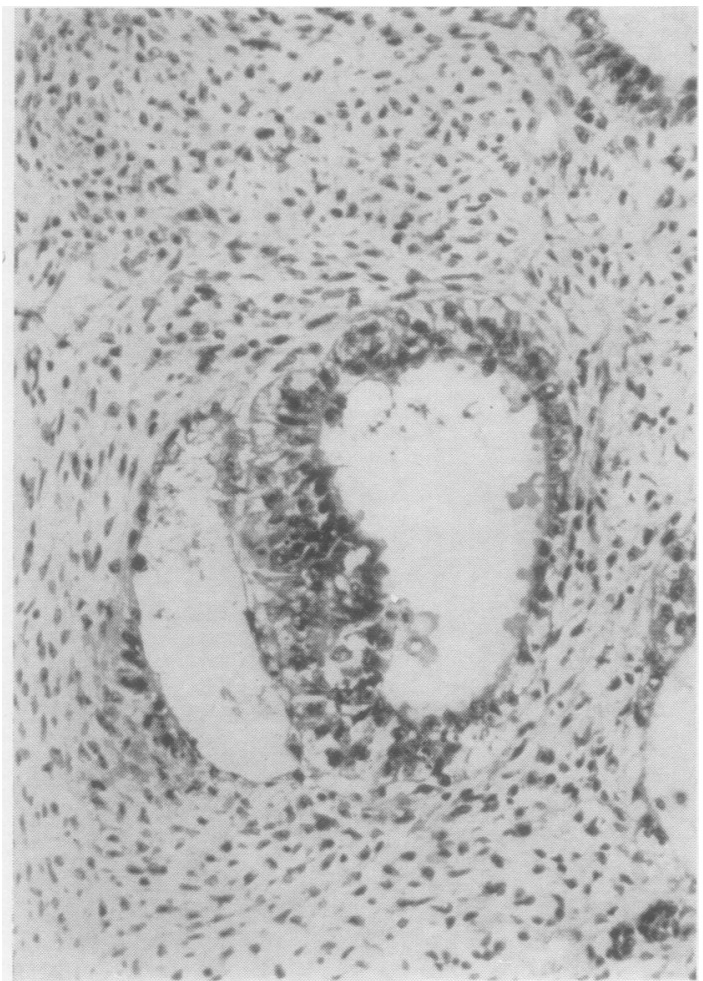

Fig. 12

EMBRYOID BODY F

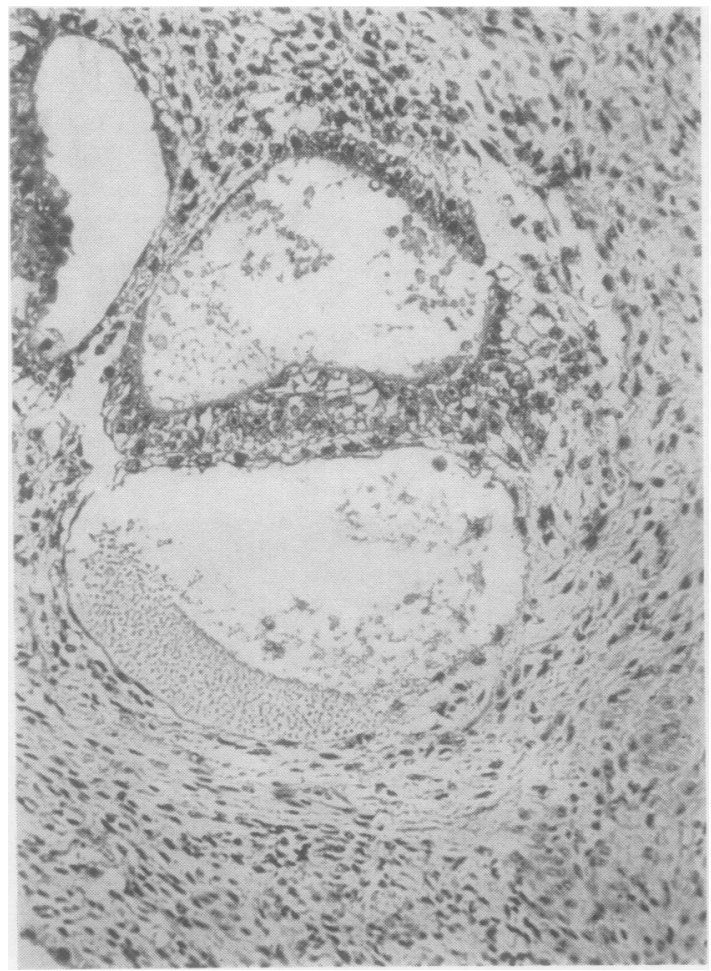

Fio. 14

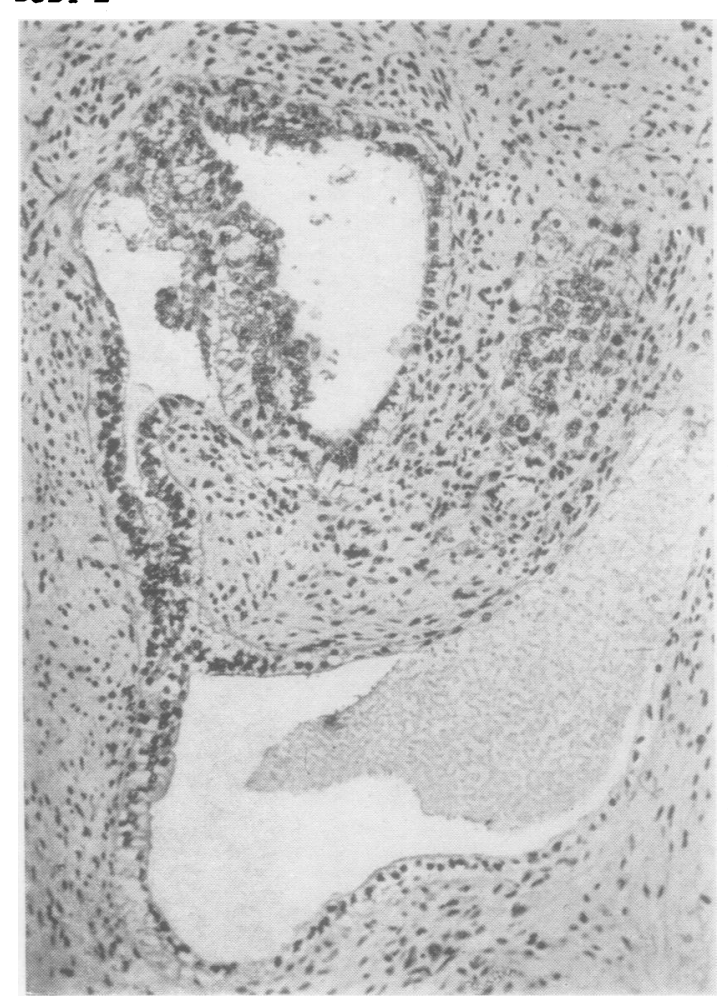

Fig. 13

EMBRYOID BODY G

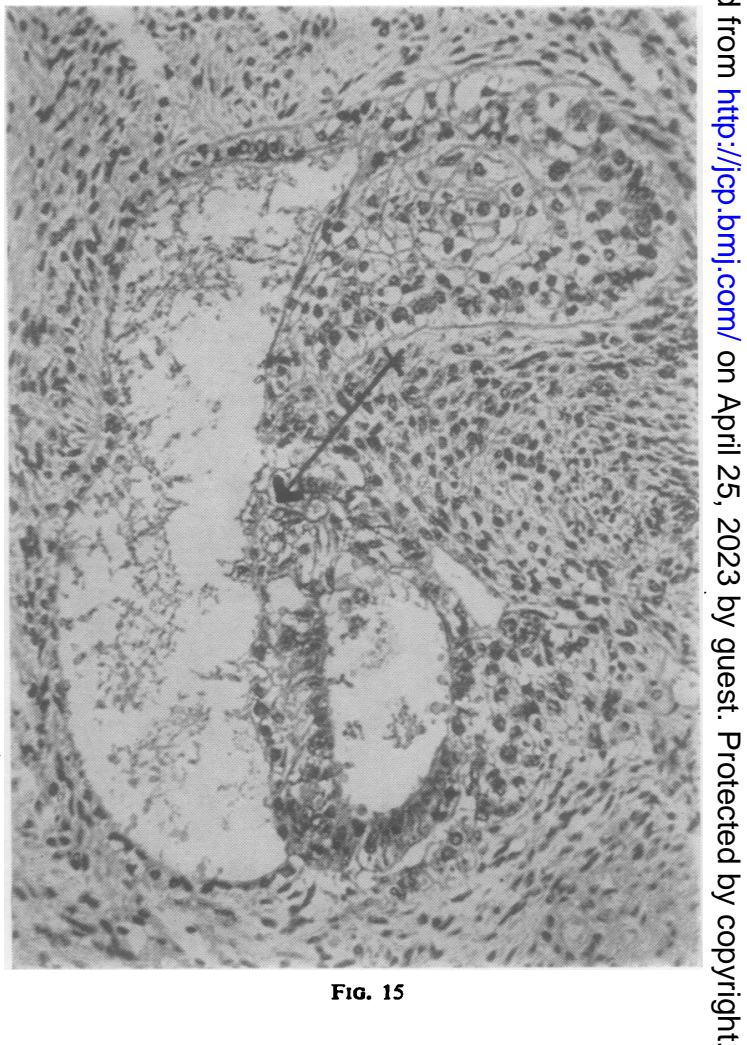




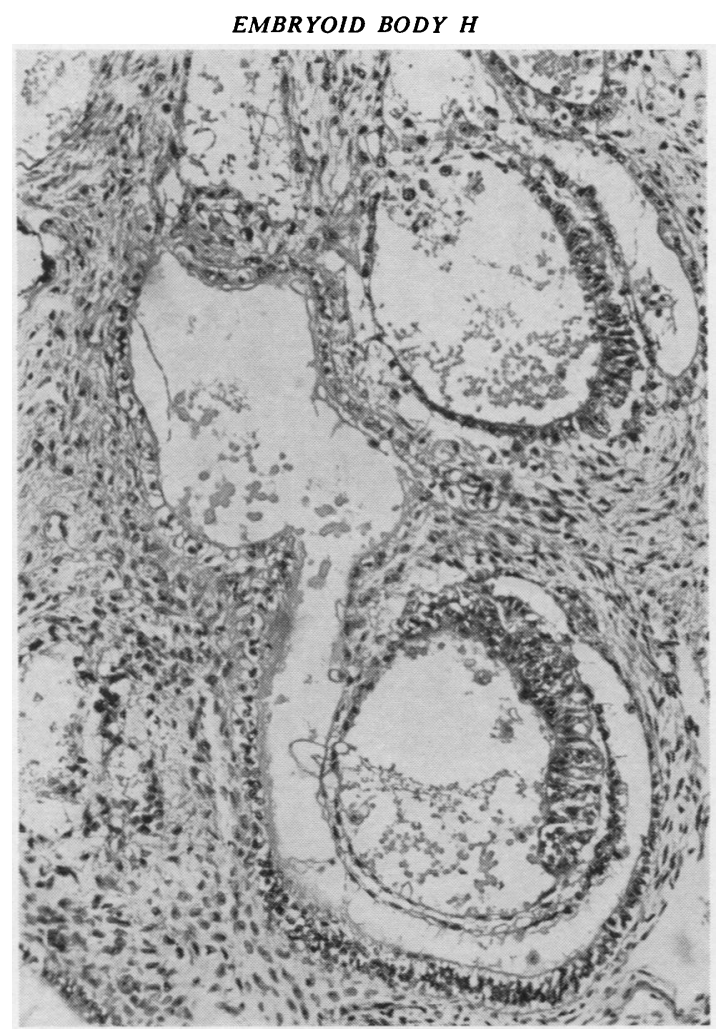

FIG. 16

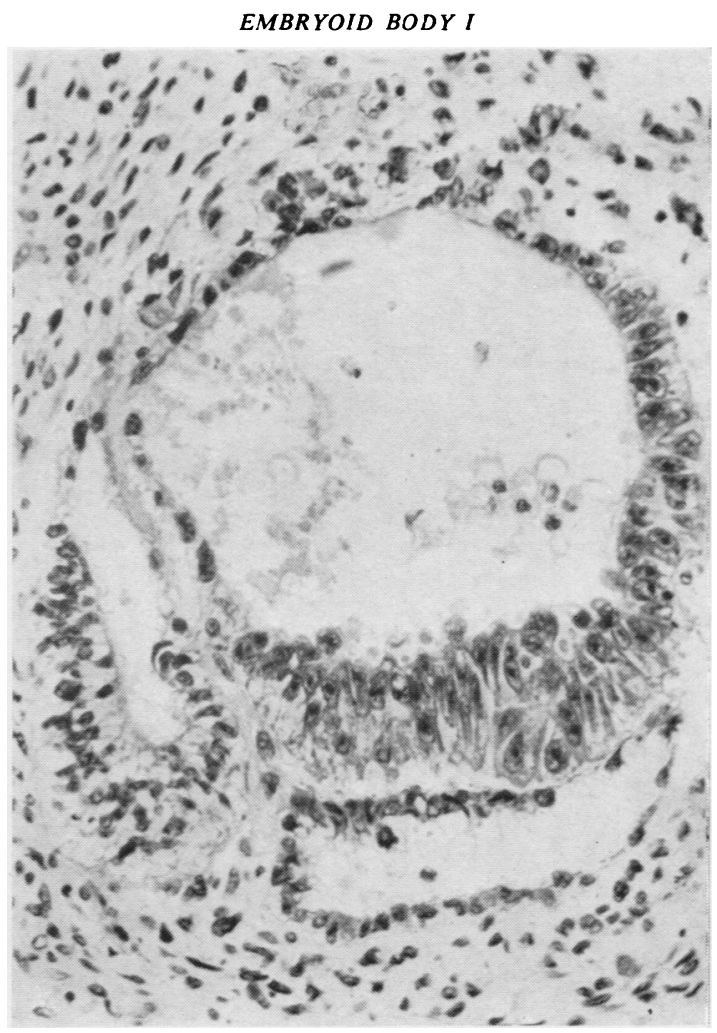

FIG. 17

FIG. 12.-Embryoid body cut through region of " primitive node and streak." Haematoxylin and eosin $\times 175$.

Fig. 13.-Extension of yolk sac of same embryoid body as in previous figure as a large " allantois" of the carnivore type. This large endodermal outpouching is not included in the measurements of the main axis of this embryoid body. Haematoxylin and eosin 120.

FiG. 14.-Embryoid body showing continuity of intra- and extraembryonic mesoderm. Haematoxylin and eosin $\times 250$.

FIG. 15.-Embryoid body showing extension of yolk sac into " body stalk" as a large type of allantois. At $X$ there is a homologue of the cloacal membrane. Haematoxylin and eosin $\times 250$.

Fig. 16.-Embryoid body showing extension of the endoderm to line a large blastocystic cavity. Haematoxylin and eosin $\times 120$.

FIG. 17.-Embryonic plate showing typical primitive streak tissue. Haematoxylin and eosin $\times 180$.

The shield consists of cuboidal and columnar cells staining darkly with their oval or elongated nuclei generally arranged in a stratified fashion to give the impression of two or more rows of cells (Figs. 12, 17). For the most part the cells are set at right angles to the free surface of the shield, but in many planes and instances their long cells

are arranged obliquely. The oblique disposition of cells and their nuclei is particularly evident in locations where the shield thickens to form an organization centre composed of tissue homologous with that of Hensen's node and primitive streak (Figs. 12, 14, 17).

In one embryoid body, which appears to be cut almost in a longitudinal plane, the endoderm of the allantois comes into continuity with the ectoderm of the amnion immediately at one end of the embryonic plate, and this connexion can be regarded as a homologue of the cloacal membrane. Suck a transition from primitive streak to "cloacal membrane" is shown in Fig. 15.

Intra-embryonic mesoderm from one to four or more cells thick is present and obvious in most well-formed embryoid bodies. These mesodermal cells are packed closely together or connected to one another by branching processes (Figs. 4, 5). At the peripheral margins of the shield they may be seen in some specimens to extend in continuity with the mesodermal cells surrounding the embryoid body (Fig. 14). No doubt, as in normal human early embryos, some of the intra-embryonic 


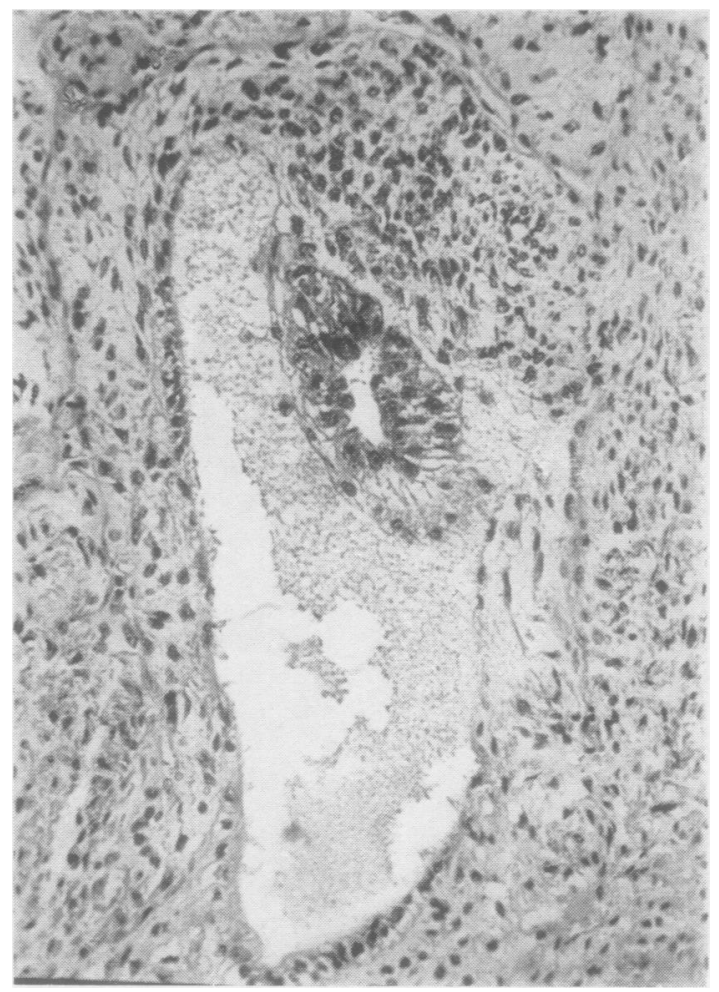

FIG. 18

FIG. 18.-Embryoid body at inner-cell mass stage showing early formation of amnion. The delaminated endoderm extends to line the blastocystic cavity. Haematoxylin and eosin $\times 250$.

FIG. 19.-Sections showing early development of amnion and exocoelomic membrane. Haematoxylin and eosin $\times 126$. mesoderm is formed by the spreading inwards of extra-embryonic mesoderm.

The elements of the middle layer sometimes fill completely the interval between the embryonic shield and the gut endoderm (Fig. 4), and in many embryoid bodies the mesodermal cells appear to issue forth from the deep surface of the embryonic disc. In some embryoid bodies an intimate relation exists between the mesoderm and yolk sac endoderm, indicating that the latter is also furnishing mesodermal elements.

\section{Diploblastic Embryoid Bodies}

Not infrequently structures were discovered which resembled the blastocystic and inner-cell mass stage of normal primate embryos. Such early embryoid bodies are depicted in Figs. 18 and 19 ; Fig. 18 in particular shows the early formation of an amniotic cavity and the delamination of the endoderm. The delaminated endoderm spreads quickly to line the blastocystic cavity, which is a relatively large sac.

\section{Caricature Triploblastic Embryoid Bodies}

Apart from well-formed, embryo-like structures there are bodies which, because of atypical morphology, appear to be caricatures of embryoid bodies, and as such their nature is not readily recognized (Figs. 20, 21). Despite distortions in morphology the occurrence of two vesicular structures in association with one another and evoking a mesodermal reaction permits their identification as homologues of early embryos. Sometimes the embryonic plate overflows down and along the wall of the yolk sac forming an additional amniotic cavity in the immediate vicinity of the latter. Further secondary differentiations, evocations, and

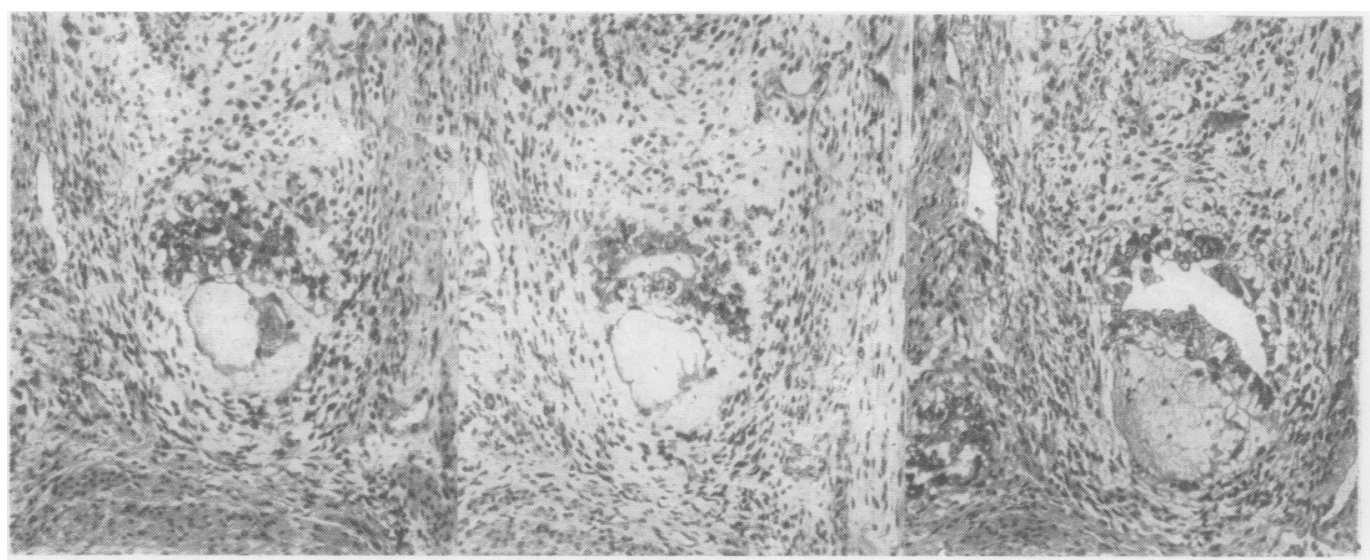

Fio. 19 


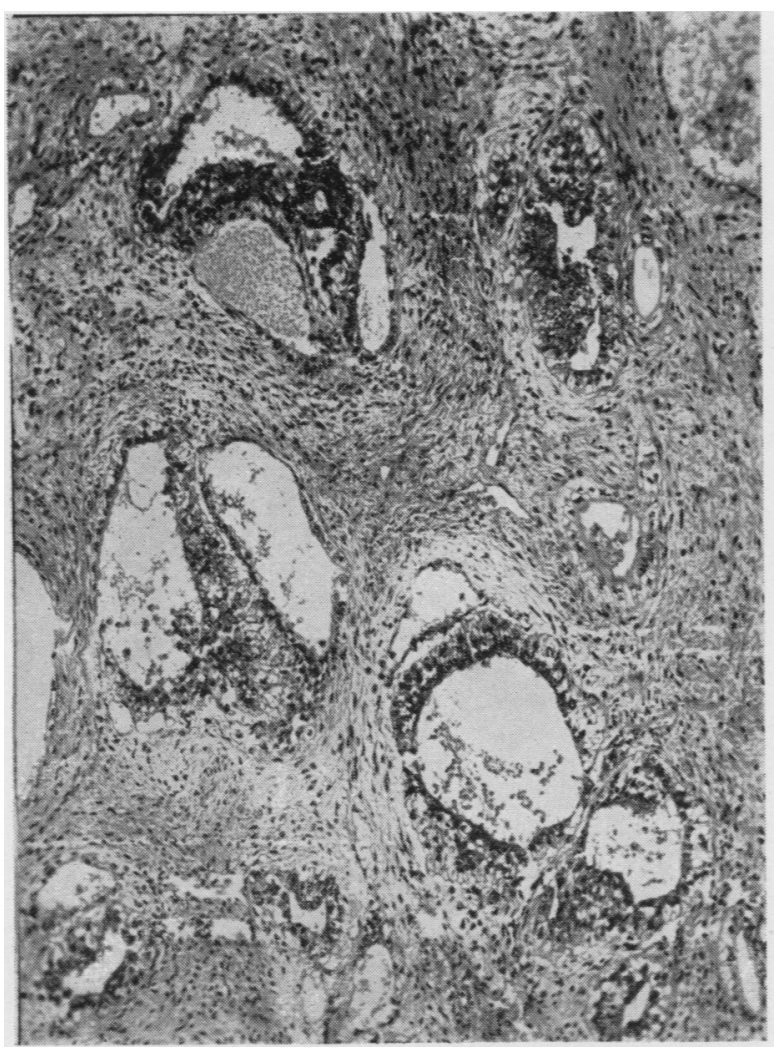

FIG. 20.-Caricature embryoid bodies; there are four in this field. Haematoxylin and eosin $\times 108$

inductions follow the spread outside the embryoid body not only of the ectodermal plate but also of the yolk sac and gut endoderm including the allantois. On other occasions ectodermal plate cells and mesodermal cells proliferate haphazardly without the formation of a shield and amniotic cavity despite the presence of a well-formed yolk sac and gut endoderm.

\section{The Development and Fate of Embryoid Bodies}

That embryoid bodies in the testes develop through stages comparable with those of normal primate embryos is obvious from a consideration of the different ontogenetic stages found in this specimen of testicular teratoma and are shown in sequence in Figs. 18, 19, 20. Stages earlier than the inner-cell mass phase are perhaps also present in this tumour, but because of difficulty in interpretation none has been identified.

The minimum age of the tumour is six months, yet the oldest well-formed embryoid body corresponds, from a morphological standpoint, with a normal human embryo of not more than 18 days of age (Fig. 1). Later developmental phases, as complete entities, were not found in the teratoma,

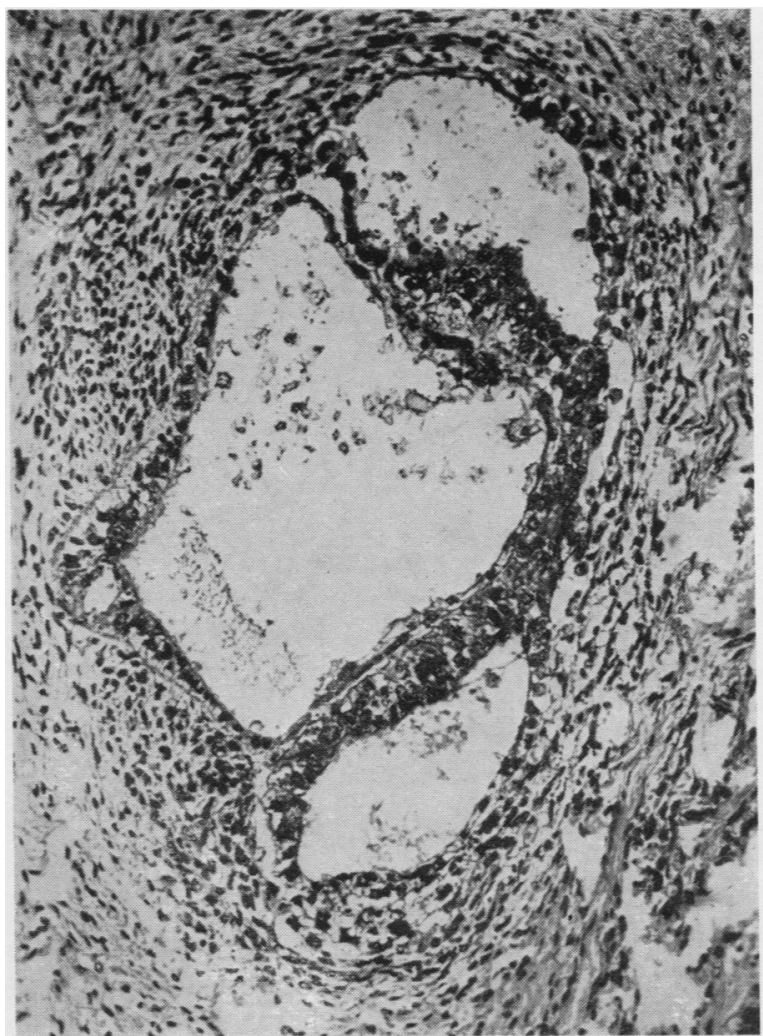

FIG. 21.-Embryoid body with two amniotic cavities. Haematoxylin and eosin $\times 150$.

and it is reasonable therefore to assume that while new embryos are being formed others disappear by losing their identity. The older embryoid bodies are obliterated by the ingrowth of mesoderm, by the over-development of a part, notably the yolk sac, gut endoderm, and allantois, and by the uncoordinated elaboration of ectodermal, endodermal, and mesodermal structures and differentiations. Such a fate may be due to lethal point mutations or to chromosomal aberrations as well as to the abnormal mode of origin and environment. Some light may be shed on environmental factors by transplantations of such tumour tissue into male and female rats and noting if further developmental stages of embryoid bodies, as complete entities, can be obtained.

\section{Summary}

The morphology and fate of embryo-like structures have been described in a teratoma testis and the various ontogenetic phases compared with those of normal presomite embryos.

\section{REFERENCES}

Dixon, F. J., and Moore, R. A. (1953). Cancer, 6, 427.

Evans, R. Winston (1956). Histological Appearances of Tumours, p. 694. Livingstone, Edinburgh.

Melicow, M. M. (1940). J. Urol. (Baltimore), 44, 333. 